University of Nebraska - Lincoln

DigitalCommons@University of Nebraska - Lincoln

Faculty Publications from Nebraska Center for Research on Children, Youth, Families, and Schools
Children, Youth, Families \& Schools, Nebraska Center for Research on

\title{
$5-2009$
}

\section{Professional Development in Early Childhood Programs: Process Issues and Research Needs}

\author{
Susan M. Sheridan \\ University of Nebraska at Lincoln, ssheridan2@unl.edu \\ Carolyn P. Edwards \\ University of Nebraska - Lincoln, cedwards1@unl.edu \\ Christine A. Marvin \\ University of Nebraska at Lincoln, cmarvin1@unl.edu \\ Lisa L. Knoche \\ University of Nebraska-Lincoln, Iknoche2@unl.edu
}

Follow this and additional works at: https://digitalcommons.unl.edu/cyfsfacpub

Part of the Pre-Elementary, Early Childhood, Kindergarten Teacher Education Commons

\begin{abstract}
Sheridan, Susan M.; Edwards, Carolyn P.; Marvin, Christine A.; and Knoche, Lisa L., "Professional Development in Early Childhood Programs: Process Issues and Research Needs" (2009). Faculty Publications from Nebraska Center for Research on Children, Youth, Families, and Schools. 13. https://digitalcommons.unl.edu/cyfsfacpub/13
\end{abstract}

This Article is brought to you for free and open access by the Children, Youth, Families \& Schools, Nebraska Center for Research on at DigitalCommons@University of Nebraska - Lincoln. It has been accepted for inclusion in Faculty Publications from Nebraska Center for Research on Children, Youth, Families, and Schools by an authorized administrator of DigitalCommons@University of Nebraska - Lincoln. 


\title{
Professional Development in Early Childhood Programs: Process Issues and Research Needs
}

\author{
Susan M. Sheridan, Carolyn Pope Edwards, \\ Christine A. Marvin, and Lisa L. Knoche \\ Nebraska Center for Research on Children, Youth, Families and Schools, \\ University of Nebraska-Lincoln \\ Corresponding author - Susan M. Sheridan, Nebraska Center for Research on Children, \\ Youth, Families and Schools, University of Nebraska-Lincoln, 216 Mabel Lee Hall, \\ Lincoln, NE 68588-0235; email ssheridan2@unl.edu
}

\begin{abstract}
In light of the current policy context, early childhood educators are being asked to have a complex understanding of child development and early education issues and provide rich, meaningful educational experiences for all children and families in their care. Accountability for outcomes is high, and resources for professional support are limited. Therefore, the early education field needs well-conducted empirical studies on which to base professional development practices. In this article, we offer research directions associated with the processes underlying professional development, including areas in need of investigation that can inform the early childhood education field in terms of how professional development efforts exert their influence and produce meaningful change in practitioners' skills, behaviors, and dispositions. The article highlights representative research from the professional development literature on its various forms/approaches and offers an agenda for research on the professional development process. Broad issues associated with the conduct of research on professional development, including considerations of professional development processes, participant characteristics, relationships, and sustainability, are discussed.
\end{abstract}

The knowledge, skills, and practices of early childhood educators are important factors in determining how much a young child learns and how prepared that child is for entry into school. Early childhood educators are 
being asked to have deeper understandings of child development and early education issues; to provide richer educational experiences for all children, including those who are vulnerable and disadvantaged; to engage children of varying abilities and backgrounds; to connect with a diverse array of families; and to do so with greater demands for accountability and, in some cases, fewer resources, than ever before. The importance of understanding the qualities of early childhood educators that contribute to optimal child learning and development has been heightened in recent years with the passage of the No Child Left Behind Act of 2001 (Public Law 107-110) and its complement in early childhood policy, Good Start, Grow Smart. In this early childhood initiative, early learning guidelines serve as a framework for practice and assessment, and individuals caring for children are required to meet certain educational qualifications and receive professional development to enhance their abilities to support young children's learning. Indeed, the professional development of practicing early childhood educators is considered critical to the quality of experiences afforded to children (Martinez-Beck \& Zaslow, 2006).

In the face of increased attention to early childhood professional development in the practice and policy communities, there is a concomitant need for empirical efforts to examine what works for whom, within which contexts, and at what cost (Welch-Ross, Wolf, Moorehouse, \& Rathgeb, 2006). Research on early childhood professional development must go beyond basic questions that address caregiver characteristics (e.g., credentials, experience) and their associations with attributes of knowledge, skill, or practice. Rather, establishing a scientific endeavor of early childhood professional development requires building a body of theories and evidence about not only its forms (i.e., methods, structures, or delivery approaches) but also its processes (i.e., underlying mechanisms responsible for or influencing change) and proximal and distal outcomes (i.e., effects on the practitioners themselves and the children/families they serve). The early childhood field is at a place where professional development practice and craft knowledge require a larger and firmer platform of theoretical and empirical expertise in order to guide planning and implementation of the ambitious kinds of school and child care reforms that are demanded in the current era of services expansion and accountability. Indeed, the field is acquiring a body of findings about the effects of various forms, levels, and organizations of professional development on early childhood educators' knowledge bases and skill sets (e.g., findings about the outcomes of different trainings, coaching, consultation, and other models of staff support). However, we need to know more about the dynamic and transactional teaching and learning processes underlying these effects as they function in real-world early childhood settings. For example, we need findings documenting personal theories of change, supportive relationships among participants, and practitioner acceptance/resistance to change. We are even farther behind in building a solid body of empirical information on the indirect but essential influence of professional development on child and family outcomes. 
The purpose of this article is to offer important research directions associated with the processes underlying professional development-that is, areas in need of investigation that can inform the early childhood education field in terms of how professional development efforts exert their influence and produce meaningful change in practitioners' skills, behaviors, and dispositions - as compared to a meta-analysis or comprehensive review of the research literature on the effects of specific forms that professional development takes. We will start by articulating the assumptions, goals, and objectives of professional development activities and by defining the forms common to early childhood professional development. This will be followed by a process research agenda that will allow us to unpack some critical features operating in the complex task of developing and promoting effective practice.

\section{ASSUMPTIONS, GOALS, AND OBJECTIVES OF PROFESSIONAL DEVELOPMENT}

At the surface, professional development in early childhood programs refers to a number of experiences that promote education, training, and development opportunities for early childhood practitioners who do or will work with young children aged birth to 8 years and their families. In this vein, professional development applies to a full range of activities that attempt to increase the knowledge base, skill set, or attitudinal perspectives brought to bear as a practitioner engages in home-visiting, parent education, child care, preschool education and/or kindergarten to third-grade teaching, or educational support services (Harvard Family Research Project, 2006). Its ultimate, long-term goal is to facilitate the acquisition of specific learning and social-emotional competencies in young children and, in many cases, to promote important family-specific attitudes or abilities to support children's learning and development. In other words, the desired long-term, indirect outcomes of all early childhood professional development initiatives involve enhancing children's learning across cognitive, communicative, social-emotional, and behavioral domains (Guskey, 2000, 2001), and such outcomes are the ultimate measure of successful professional development initiatives.

In a more immediate sense, professional development in early childhood takes place to accomplish two primary objectives. First, it is anticipated that professional development will advance the knowledge, skills, dispositions, and practices of early childhood providers in their efforts to educate children and support families. A second objective is to promote a culture for ongoing professional growth in individuals and systems (Candy, 1991; Johnson \& Johnson, 1989). The first objective concerns the advancement of practitioner knowledge, skills, and dispositions (Katz, 1992, 1995). Practitioner knowledge consists of facts, concepts, ideas, vocabulary, and related aspects of educational culture and best practice. Skills 
consist of units of action that occur in a relatively discrete period of time and that are observable or easily inferred. They are learned through direct instruction, modeling and imitation, trial and error, discovery, or other methods, and they are modified or improved through feedback, guidance, practice, repetition, drill, and continuous use. Finally, dispositions are prevailing tendencies to exhibit a pattern of behavior frequently, consciously, and voluntarily. The pattern of behavior is directed to a broad goal rather than a limited, short-term purpose. Dispositions are distinguished from skills in being broader in scope and including a motivation to be applied and put to use (in contrast, one can have a skill but no desire to use it). Benefits of professional development efforts that target knowledge, skills, and dispositions may be expected in teachers' interactions with children or families, teachers' efforts to structure meaningful learning environments in the home or classroom, teachers' use of specific curricula or teaching strategies for a particular group of children, or teachers' use of a host of other specific behaviors or meaningful targets.

The second objective of early childhood professional development involves sustaining high-quality professional practices by enhancing systems and individuals to engage in activities that are self-sustaining and growth producing. This involves ensuring that the responsibility for delivering effective services and facilitating ongoing growth and development among practitioners is transferred from a formal trainer (coach, consultant, group facilitator) to individuals and groups of professionals within early childhood settings. Imparting an ethic of responsibility for sustaining quality and ongoing growth and learning in practitioners first involves efforts to help individuals develop the skills and dispositions for self-regulated professional growth (Fleet \& Patterson, 2001; Paris \& Winograd, 1990; Riley \& Roach, 2006). Initially, professional development is expected to be an "outside-in" process, wherein the information necessary for behavior change or professional growth comes from external authorities, imparted through lectures, readings, demonstrations, and verbal advice from peers, supervisors, coaches, or consultants. Later, however, professional development ideally progresses to becoming an "inside-out" process in which individuals retain responsibility to direct their own ongoing growth and improvement through continued study of current and best practices and reflective personal goal setting in collaboration with respected colleagues (Helm, 2007; Wesley \& Buysse, 2006).

\section{FORM AND PROCESS IN PROFESSIONAL DEVELOPMENT FOR EARLY CHILDHOOD PRACTITIONERS}

Understanding what is involved in practitioners' acquisition of knowledge and skill, and changes in disposition and practice, requires efforts to 
uncover underlying aspects of both the form and process, as well as their interactions and the various mediators and moderators that influence their effects. In the following section we provide a definition for widely accepted forms of professional development for early childhood education practitioners, followed by a representative sample of research associated with these forms. This is followed by a presentation of research needs, particularly in areas that highlight processes to address questions of "how" or "why" certain professional development efforts promote or impede growth, rather than "what" professional development forms effect change in early childhood educators.

\section{Forms of Professional Development}

Most structural definitions of early childhood professional development identify it by its various forms of organization. In general, professional development efforts have traditionally taken five forms: (a) formal education; (b) credentialing; (c) specialized, on-the-job in-service training; (d) coaching and/or consultative interactions; and (e) communities of practice (CoPs) or collegial study groups (Zaslow \& Martinez-Beck, 2006). Although formal education (degree earned prior to employment) and credentialing (agency or organizational qualifications or standards) fall under the umbrella of a professional development structure, our intent is to focus on those forms and related processes of professional (or "staff") development most commonly associated with employed practitioners. We refer readers to other extensive sources that describe education and credentialing practices and research (e.g., Maxwell, Field, \& Clifford, 2006) and will not review that literature here.

Specialized training. Training in early childhood in-service contexts is composed of activities specific to early childhood programs and populations that take place outside of a formal educational system and that provide specific skill instruction or skill-building content for on-the-job application (Maxwell, 2006; Tout, Zaslow, \& Berry, 2006). Training events and activities may include workshops, conferences, in-service presentations, live or Web-based lectures or discussions, live or video demonstration, behavior rehearsal, manuals, tutorials, and a host of other modes, synchronous and asynchronous, that impart knowledge and information and attempt to affect professional practice. Although similar forms of instruction are used in both formal preservice education and on-the-job in-service training programs, the latter tend to be shorter in duration (e.g., one session, 3 days vs. 10-16 weeks) and to have fewer opportunities for repeated contact with instructors for clarification of information. Most in-service training programs use a format that provides generalized knowledge and information to groups of early childhood practitioners with limited followup or feedback on observed practice (Pianta, 2006). Trainers are often con- 
sidered to be expert sources of information and the trainees to be novice learners acquiring targeted knowledge or skills. The training format typically provides brief, non-sustained contacts between trainer and trainee, and the flow of information is most often one-directional. Hypothetical cases or trainee-reported situations may be used to rehearse the application of new principles or skills within the training context but are usually of limited familiarity to all trainees and the rehearsals short in duration and intensity (i.e., one example, one-minute practice).

Coaching/consultation. Coaching to advance early childhood professional development is a "voluntary, nonjudgmental, and collaborative partnership that occurs [between early childhood professionals] when one desires to learn new knowledge and skills from the other" (Hanft, Rush, \& Shelden, 2004, p. 1). The goal of coaching is typically focused on direct efforts to improve the trainee's learning and application of child-specific interventions or teaching strategies. Core components of coaching in early childhood settings include reinforcing evidence-based skill development and application of desired skills in the form of teaching practices with children and families. Coaching requires crafting knowledge of new skills and practices to fit the personal styles and values of early childhood practitioners in their applied settings (Fixsen, Naoom, Blase, Friedman, \& Wallace, 2005). Hanft et al. described coaching in early childhood settings as including independent and/or shared observations, action (demonstration, guided practice), self-reflection, feedback, and evaluation of the coaching process/relationship. This process generally calls for frequent interactions over a relatively short period of time to effect change in the practitioner's behavior, attitude, and/or disposition.

Consultation is closely related to coaching. Consultation in early childhood settings has been defined as an indirect, triadic model that focuses on helping the consultee (trainee) in his or her professional responsibilities with one or more clients through systematic problem solving, social influence, and provision of professional support for an immediate concern or goal desired by both trainee and client(s) (e.g., Buysse \& Wesley, 2005; Farrer, Alkon, \& To, 2007; Sheridan \& Kratochwill, 2008). Depending on the situation, the consultant can be perceived as an authority and can convey an expert-like stance on various content or practice dimensions of early childhood service delivery. However, it is generally accepted that the manner in which the consultant's expertise is used in professional development situations is through supportive, collaborative exchanges. Much like coaching relationships, the frequency of contacts between a consultant and learner is typically high in the early stages and lessens over time as the teacher becomes more proficient at acquiring and demonstrating strategy use in applied settings. Thus, the duration of the consultation relationship is determined based on individual need, and the nature of most consultative relationships is highly individualized (Sheridan \& Kratochwill, 2008). Despite the fact that distinctions can be made in early childhood profes- 
sional circles, we consider coaching and consultation to be highly related forms of professional development and consider them together in the remainder of this article.

Communities of practice. Training and coaching represent relatively short-term and small-scale learning encounters. Communities of practice are a form of ongoing professional development that is becoming more widely known in the field of early childhood education and intervention (Helm, 2007; Wesley \& Buysse, 2006). Communities of practice are defined as groups of individuals who come together on the basis of a common professional interest and a desire to improve their practice in a particular area by sharing their knowledge, insights, and observations (Wenger, 1998; Wenger, McDermott, \& Snyder, 2002). Lave and Wenger (1991) first used the term to describe the situated learning that takes place in apprenticeship, a learning model that involves a complex set of social relationships by which experts pass on knowledge to novices. The concept overlaps with related terms used in education to describe situations in which the experts are teachers themselves learning from one another as they study their students' work and lesson plans. This approach to improving teacher practice is closely related to teacher action research in early childhood (Stremmel, 2008; Yorks, 2005) and is described under such diverse labels as descriptive review of student work (Himley \& Carini, 2000), lesson study (Lewis, 2002), co-inquiry (Abramson, 2008), collaborative analysis of student work (Langer, Colton, \& Goff, 2003), and documentation study (Peaslee, Snyder, \& Casey, 2007; Project Zero et al., 2003).

CoPs have been used to support professional development in a variety of settings, including schools and child care programs (Bray, Lee, Smith, \& Yorks, 2000). Groups can include organization-specific members or a mixture of agency-employed teachers and external facilitators. CoP meetings require an expert facilitator who has relevant experience and practical wisdom and can help the group ask questions, connect and build ideas, expand key points, provide history and useful resources, and stay on task (Kennedy, 2004). As such, the relationships can be characterized as bidirectional, with information transferring from facilitator to participant and back. In CoP meetings, which take place face to face or electronically in a virtual community, participants focus on issues, problems, and successes that emerge from authentic situations in their work. This allows for the experience to be highly relevant and applicable for participants. Many groups use a formal protocol for guiding participants in offering reactions, raising questions, and brainstorming next steps. The participants can create and reflect on specific plans and feedback for their own work settings. The goal of these communities is to reduce the research-to-practice gap as well as create self-sustaining networks of stakeholders focused on translating, applying, and in some cases producing new evidence in early education by integrating research findings from scientists with experiential knowledge from practitioners. 
Research related to forms of professional development. Much is now known about the five forms of professional development. ${ }^{1}$ Originally it was thought that higher levels of formal education, especially that which produces specialization in early child development or education, related to higher quality early childhood programs and improved interactions between teachers and children (Pianta, 2006; Tout et al., 2006). However, a recent comprehensive review by Early et al. (2007) of seven large-scale studies found little relationship between teachers' level of education and overall classroom quality or academic outcomes for children. Furthermore, empirical studies have not provided adequate information about minimum levels of education required for early childhood educators (Tout et al., 2006); thus, teacher quality in early childhood programs can be considered a function of much more than teachers' education level alone. These findings suggest that empirical, process studies are needed that look beyond education and credentialing in order to reach a more complete understanding of effective professional development practices.

A recent meta-analysis found that specialized training does in fact improve the competencies of early childhood teachers, including their attitudes, knowledge, and skills (Fukkink \& Lont, 2007). More effective trainings aim to ensure opportunities for trainees to practice key skills in the training setting (Joyce \& Showers, 2002) and provide feedback on the practice of new teaching skills immediately or later on the job (Maloney, Phillips, Fixsen, \& Wolf, 1975). Behavioral rehearsal (e.g., practice, role playing) of new skills and individualized feedback are often recognized as important phases in staff development efforts (Blase, Fixsen, \& Phillips, 1984; Joyce \& Showers, 2002; Kealey, Peterson, Gaul, \& Dinh, 2000).

Another meta-analysis on the outcomes of different training methods for teachers (not limited to early childhood educators) revealed that multidimensional methods of training produce positive effects in knowledge and skill acquisition (Joyce \& Showers, 2002). Furthermore, different components of training appear to be important depending on the goal of professional development. For example, when knowledge is an objective of training, information combined with demonstrations, practice, and feedback increases knowledge more considerably (effect size $=1.31$ ) versus information-giving alone (effect size = 0.5; Bennett, 1987; Showers, Joyce, \& Bennett, 1987). When skill development is the goal of the professional development efforts, the addition of practice to the discussion of theoretical rationale or demonstration often results in effect sizes of 1.18 versus 0.5 without practice. Furthermore, when coaching is added, skill acquisition continues to increase and transfer of learning to work with children is more likely. Trans-

1. Extensive reviews of the literature on forms of professional development are available elsewhere (e.g., Fukkink \& Lont, 2007; Joyce \& Showers, 2002; Zaslow \& MartinezBeck, 2006). Thus, we draw from this work rather than duplicate it and focus instead on necessary directions for research on professional development processes to advance the empirical base in early childhood. 
fer of learning to the work setting is not achieved without some ongoing support following training (Davis, 1995; Joyce \& Showers, 2002).

Few studies have assessed the impact of training on participants' implementation of targeted training content in work settings. Some research evidence indicates that training on early childhood curricula and practices is positively related to teachers' sensitivity and language enrichment in their interactions with young children (Clarke-Stewart, Vandell, Burchinal, O'Brien, \& McCartney, 2002; Dickinson \& Caswell, 2007), thereby positively enhancing early childhood programming and quality. Another study indicated a relationship between training and procedural fidelity of a language and literacy intervention, but limited generalization to more complex facilitation of child language (Justice, Mashburn, Hamre, \& Pianta, 2008). Evidence that causal links exist between caregiver training and positive effects on children's behaviors is still uncertain, however, with at least some studies suggesting that the link exists (Girolametto, Weitzman, \& Greenberg, 2003; Rhodes \& Hennessy, 2000) and others indicating that it is not education or training alone that contributes to positive outcomes (Early et al., 2007). The general consensus from research reviews and summaries is that teachers' implementation of new skills occurs primarily when specific training is combined with on-the-job coaching. Use of consultants/ coaches for feedback on observed performance, supervision of systematic plan development and implementation, and support for ongoing challenges and decision making appears to be necessary for changes in teachers' performance (Ager \& O'May, 2001; Joyce \& Showers, 2002).

Furthermore, CoPs have been reported as influential in supporting sustained changes in practice (Wesley \& Buysse, 2006). The evidence base examining application and outcomes of CoPs in early childhood education is small but growing. Most studies to date have focused on the benefits of strong staff collaboration in changing practitioners' beliefs and practices but not always as a follow-up to specialized training or coaching for targeted behavioral change (Greene, 2004; Taylor, Pearson, Peterson, \& Rodriguez, 2003, 2005). Particularly necessary is research that examines the efficacy of CoPs in sustaining quality early childhood programs and the mechanisms by which they support ongoing growth of early childhood practitioners, individually and collectively.

\section{Process Definitions}

The process of professional development refers to how professionals move from awareness (knowledge) to action (practice) and to the adoption of particular dispositions in their professional repertoires. This process is not believed to be linear, nor is it believed to be limited to a set of particular inputs and outputs. Rather, the process is considered a dynamic enterprise composed of transactive experiences and interactions among individuals in complex systems (Fleet \& Patterson, 2001). Definitions of professional de- 
velopment in process terms focus on the ongoing and responsive efforts to improve an individual's skills and competencies (Ramey \& Ramey, 2008). For example, stage models of professional development address the process of skill acquisition by specifying the steps through which a learner moves from novice to expert understandings of professional practice. The adoption of new professional practices is often acknowledged as a process that moves through at least three stages: (a) awareness of new strategies that are expected to achieve important child outcomes; (b) application of these strategies, at first in a somewhat awkward fashion; and (c) refinement of these skills so that they are implemented automatically and in a practiced, masterly manner. Hall and Hord (2001) suggested that practitioners first focus on impacts of the new concepts and practices on their own well-being, transition into mastery of the concepts or skills, and end with a focus on the impact of the practices they are implementing on children and families. Dreyfus and Dreyfus (1986) articulated yet another stage model whereby learners proceed through a series of stages defined as novice, advanced beginner, competent, proficient, and expert. Throughout this stage-wise progression, learners advance from concrete, rule-governed approaches to tasks, to flexible use of plans, to intuitive and seamless use of strategies.

Stage-like models in the study of early childhood professional development are useful for conceptualizing basic processes by which professionals acquire new concepts and adopt new skills. However, they fail to define exactly what constitutes skillful practice and assume that the content of these skills is irrelevant. In other words, the focus of most stage models is on a generic process that is presumably identical across professionals irrespective of context variables (i.e., discipline, setting) and content (i.e., the skill that is being developed and learned).

In contrast to stage models, Dall'Alba and Sandberg (2006) offered a contextual, albeit theoretical, explanation of professional skill development, suggesting that skill acquisition is accounted for as professionals develop an "understanding of, and in, practice" (p. 388). From this perspective, advanced skill levels are achieved through experience and practical application in "real-work" situational contexts. Contextualized knowledge and experience are thus intertwined and interdependent. This conceptualization of professional development understands process as an ongoing and fluid interaction of instruction with experiences, opportunities, and exchanges that occur in a reflexive and transactional manner as specific professional practices within a particular setting are defined, achieved, and reformulated toward continual self-improvement and program standards. In a similar vein, VanderVen (1988) conceptualized a developmental sequence toward professionalism going from novice to "influential." This model is considered to be ecologically based (Spodek, 1996) because it ties professional development to career development and to the degree of differentiation of roles that teachers must assume in different positions and the amount of supervision required for effective practice. 


\section{RESEARCH NEEDS IN PROFESSIONAL DEVELOPMENT IN EARLY CHILDHOOD PROGRAMS}

The current state of professional development in early childhood programs indicates that much more is known about what professional development is (i.e., its structure or form) than how it operates to promote new knowledge and skills (i.e., the process). Indeed, little empirical research has been dedicated to the process by which early childhood practitioners acquire new knowledge, skills, and dispositions. Even less attention has been afforded to mechanisms for sustaining individual and group growth and development. Much of the research on stage models or contextual explanations is theoretical and is not based on empirical findings. Further research on process is necessary to unpack elements through which various professional development forms influence the skill, knowledge, and dispositions of early childhood professionals. That is, beyond asking questions of efficacy (e.g., "Does this approach work?"), process research is needed to discern what about particular forms of professional development (e.g., training, coaching, CoPs), individually and in combination, impact practice. Indeed, implementation aspects associated with various professional development strategies (e.g., demonstration, observation, practice, feedback, direct and indirect guidance, reflection, scaffolding, collaborative study) are worthy of systematic study and comparison. For example, the timing and intensity of strategies such as focused feedback and/or personal reflection appear to be important for an early childhood teacher to receive positive effects from the professional support for development; however, the balance among these and other strategies, and their individual and collective effects, are only beginning to be understood (Hattie \& Timperley, 2007).

In this section, we integrate the gaps in the research literature identified heretofore and carve out a research agenda for early childhood professional development. We focus less on identifying and investigating what structures need to be in place and more on research needs that will allow the field to determine how learning and skill acquisition can be accomplished in the early childhood professional context. Interacting with issues related to processes surrounding knowledge and skill acquisition are questions about roles, relationships, and systemic issues that may mediate and/ or moderate the effect of professional development on professional practice. Specifically, an empirical research agenda is offered that identifies the importance of determining processes that influence fundamental change in knowledge, skills, and dispositions; variables that influence their effects (e.g., relationships among participants; systemic, contextual, and policy variables); and procedures to create cultures for ongoing quality among individuals and systems (e.g., self-regulation and development). Potential research questions within each area are presented in Table 1. Indeed, the issues and questions raised here present avenues for systematic inquiry. 
Table I. Possible Research Questions for Early Childhood Professional Development

Process Variables in Professional Development

I. (How) Do the various forms of professional development (i.e., specialized training, coaching/consulting, and communities of practice), individually and in combination, promote (a) increased knowledge, skill, dispositions, and practices among early childhood practitioners; and (b) a culture for ongoing professional growth?

2. What elements or components of each of the forms of professional development contribute to positive and lasting change? How do these components function to effect change in knowledge, skills, dispositions, and practice?

3. What is the process by which early childhood practitioners move from a focus on mastery of intervention implementation to self-regulated professional growth?

4.What is the best mechanism for scaffolding practitioners' skill development over time? What is the developmental course for skill development, and how does that interact with coaching strategies?

5. (How) Does reflection on intervention and practice relate to/predict change in practice or ongoing development? Does it mediate the effects of professional development?

6. How does delivery of training/coaching/consulting (e.g., face to face;Web-mediated; group vs. individual) affect skill acquisition and practice?

7.What strategies do effective coaches/trainers/facilitators use? What specific behaviors of the trainer, coach/consultant, and facilitator lead to observed change and positive growth in the early childhood practitioner?

8.What supports do coaches need to be most effective?

9.What are the functional mechanisms/strategies that facilitate meaningful self-reflection in early childhood practitioners?

10. What types or forms of feedback are effective at producing which outcomes? What are the elements of feedback that influence knowledge and behavior change?

II.What professional development strategies facilitate fidelity of intervention implementation?

12. How are professional development efforts related to outcomes of children and families for whom early childhood educators are responsible?

13.What is the relationship between competency and decision-making skill in a coach/ consultant and the associated change in skill and practice among learners?

14. What is the process by which coaches, consultants, and facilitators make decisions about practitioners' needs and select strategies to scaffold their learning, promote their skill acquisition, and facilitate their change in practice?

\section{Personal and Relational Variables in Professional Development}

I.What makes an effective coach/consultant/facilitator? What makes an effective learner?

2. How do characteristics of the coach and of the early childhood educator influence the professional development relationship?

3. How do personal characteristics of the early childhood practitioner (e.g., beliefs, values, role construct, readiness for change) relate to knowledge and skill acquisition and to readiness for change?

4.What is motivating to facilitate professional change? What is an effective incentive?

5.What is the effect of an early childhood professional's conceptualization of the link between his or her practices and child/family outcomes?

6. What factors influence the best fit between coach and practitioner? 
Table I. (continued)

7.What is the influence of trust, shared goals, respect, commitment, and other intangible relationship qualities on coaching effectiveness?

8. Does a positive trainer/coach/practitioner relationship mediate the effects of professional development on practitioner change?

Contextual and Systemic Variables in Professional Development

I.What factors within the early childhood agency or work environment influence uptake of professional development efforts? How do they effect change in skill/practice?

2.What is the influence of an agency's culture on uptake and maintenance of effective professional development outcomes?

3. How does professional work setting (school vs. home) or context (Early Head Start, Head Start, public or private pre-kindergarten) influence professional development delivery or uptake?

\section{Means to Promote Sustained Change}

I.What actions engaged in by individuals and agencies produce long-term maintenance and institutionalization of professional change?

2.What intensity and duration of coaching is needed to promote sustained change?

3. What are the costs of effective professional development models? How much does it cost in terms of resources on the part of trainers, coaches, and practitioners? What resources and supports are necessary to produce results?

4. What is the effect of communities of practice on climates for ongoing professional growth? How do personal and relational variables in work settings interact with communities of practice?

5. How do agencies sustain effective professional development activities once external resources are removed? How do programs sustain best practices in professional development once external resources are removed?

\section{Process Variables in Professional Development}

Although it is clear that ongoing, supportive experiences in field-based settings are more beneficial than instruction alone in promoting skills and behavior change (Joyce \& Showers, 2002), the manner in which these components of professional development relate to behavior change and maintenance is not sufficiently understood. Questions surround the various forms of professional development and how they independently and collectively promote the goals of personal and professional growth (increased knowledge, skills, dispositions, practices, and self-regulation). Research that attempts to determine how professionals achieve new levels of understanding and translate that understanding into skillful practice is necessary. A research agenda focused on process should be concerned with uncovering the transactions between learning new content (horizontal learning) and acquiring deeper understandings of use within on-the-job practice settings (vertical learning). It is important to understand how practitioners develop skills over time, how they simultaneously achieve deep understandings, and which professional development efforts support these processes. The 
role of self-reflection in becoming a consistent learner is also worthy of research attention.

Presently there is little research investigating functional and effective behaviors used by trainers, coaches, and consultants (Knoff, McKenna, \& Riser, 1991) and their relationship to targeted behavior change (e.g., practitioner's implementation of intervention plans with fidelity). A host of descriptive studies have suggested qualities in coaches and consultants that appear to be important within professional development relationships, but few have identified specific functional behaviors that lead to growth and learning among early childhood practitioners. Resources on coaching in early childhood have suggested that competency, objectivity, adaptability, caring, and honesty are characteristics of an effective coach (Hanft et al., 2004). Additionally, effective coaches have been described as mentors who are encouraging; supportive; committed; sensitive; flexible; respectful; enthusiastic; diplomatic; patient; and willing to share information, credit, and recognition (Green, Everhart, Gordon, \& Garcia-Gettman, 2006; McCormick \& Brennan, 2001). In the consultation literature, characteristics such as effective communication skills, a well-developed knowledge base, problem-solving abilities, and a collaborative attitude have been identified as important qualities in a consultant (Cannon, Idol, \& West, 1992). However, the literature on professional development in early childhood programs has not yet systematically justified these individual qualities beyond consumer surveys and reports (McWilliam, Tocci, \& Harbin, 1998).

Research is needed that determines precisely what effective coaches and consultants do to elicit desired qualities and competencies of practitioners and that identifies why this is important in terms of creating productive learning sessions that lead to lasting changes in skills and practices among learners. Specific strategies used by coaches, and their association with the range of desired outcomes of professional development (e.g., practices, self-reflection), need to be unpacked to understand their utility. In addition, given the proliferation of alternative mechanisms for the delivery of professional development (e.g., Web-based and face to face, group and individual formats), study of the influence of structure on uptake and outcomes is necessary. Indeed, the outcomes of specific professional development forms on the fidelity with which evidence-based practices are delivered and the indirect effects on child outcomes are in need of research attention. Understanding the critical components and principles underlying the forms of professional development may allow for flexibility in implementation (e.g., effective strategies used by both trainers and coaches) without sacrificing the function associated with any one approach to professional development (Fixsen et al., 2005). For example, further investigation is needed to elucidate effective mechanisms used by coaches to scaffold professional skill development over time, particularly for complex professional skills such as engaging families in learning; promoting early literacy, science, and mathematics; and enhancing English language learners' early academic competencies, to name a few. 
Coaches, consultants, trainers, and facilitators make several decisions regarding the direction of the professional development of practitioners with whom they work, including the assessment of each early childhood teacher's current knowledge and skill, determination of presenting needs for professional development, methods to promote attainment of new strategies, and timing of activities to move the teacher from basic knowledge and skill enactment to more complex foci related to self-regulation and ongoing professional growth. Methods by which trainers, coaches, consultants, and facilitators make decisions for scaffolding teachers' learning comprise a set of complex variables that have not been the subject of research. Additional research is needed that investigates the professional supports and education needed by coaches to make decisions, the relationship between a coach's competency and decision making, and associated changes in an early childhood practitioner's skill development and approach to practice. Furthermore, the indirect effect of training/coaching/consulting on important child and family outcomes requires further study (Early et al., 2007).

\section{Personal and Relational Variables in Professional Development}

Within-person variables. Personal and professional characteristics of practitioners and coaches and trainers that can influence professional relationships are potential sources of variance that may affect the manner in which professional development efforts are delivered and received and, hence, the desired outcomes. For example, although it is clear that coaching can bring many benefits to the quality of practitioners' efforts with children and families, many factors impact the effectiveness with which coaching is utilized. Effective coaching, consulting, and group facilitation depends on the availability of staff who have expertise in the rationale, content, and techniques of targeted skills and practices promoted in training programs. Indeed, background characteristics of the trainer/coach/consultant/facilitator, such as his or her own education, training, knowledge base, theoretical orientation, perception of roles, and experience, likely predict his or her effectiveness and the subsequent impact on teachers' professional development. These variables, and the manner in which they affect training, coaching, CoPs, and relationships, are in need of investigation.

An early childhood teacher's current level of understanding, based in part on previous background and education, can interact with training, coaching, and CoPs in ways that are not well understood. Research on the effect of a teacher's education on the quality of the classroom experiences has suggested that factors beyond education alone are important in predicting positive outcomes for children (Early et al., 2007). Additional intrapersonal characteristics of the early childhood educator (e.g., theoretical orientation, view of self and role as teacher and effective change-agent, beliefs about children's learning, and attitudes about work and coaching) also appear to be important in one's readiness and willingness to change 
(Dall'Alba \& Sandberg, 2006; File, 1994) and may moderate the effects of professional development efforts on professional practices, even when those practices are delivered by competent, experienced trainers, coaches, or facilitators. Research on dispositional and personal characteristics of early childhood practitioners, their interaction with forms and approaches to professional development (training, coaching/consulting, CoPs), and their influence on the efficacy of professional development interventions is needed.

Relationships between person and practice are important in the delivery and uptake of professional development efforts (Gallacher, 1997) and represent fruitful areas for further research. It still remains the exception rather than the norm for research attention to be paid to professionals' own understandings of current and proposed practice. Yet learning and development cannot be understood without recognizing the practitioners' conceptual models of practice or role theories that may interact with those of a trainer, coach, consultant, or facilitator and present challenges to achieving more complex or comprehensive outcomes (Dall'Alba \& Sandberg, 2006). The manner in which practitioners conceptualize their practice is fundamental to their potential acceptance, internalization, and generalization of training and coaching (Fleet \& Patterson, 2001). For example, early childhood practitioners who perceive their role as delivering information to children and families will likely engage in activities that focus on presenting content in formal teaching interactions. Subsequently, in-service training or coaching that aims to promote the use of mutual problem solving with families or experiential learning with children will likely be met with some resistance or delays in the practitioners' application of suggested practices. In contrast, practitioners who view their role as facilitating learning may engage parents and children in significantly different ways through, for example, natural settings and learning opportunities as potential conduits for promoting decontextualized and generalized learning. Lack of appreciation for prior values, theories, or conceptions of practice may limit the potential of professional development efforts to the extent that it reinforces existing understandings of professional roles rather than advances fundamental change in conceptualizing and enhancing work with children and families (Dall' Alba $\&$ Sandberg, 2006). The degree to which these personal and relational variables impact professional development efforts is in need of research.

Motivation for change in the early childhood teacher likely affects the training and training/coaching/consultation process and efforts to guide positive growth. However, what motivates change in professional behaviors is not clear. It can be assumed that practitioners who are motivated and "ready" to change have an outlook or perspective that change in their own behaviors will result in positive outcomes for children. Such practitioners demonstrate a willingness to approach their role flexibly and will take advantage of learning opportunities provided (Duff, Brown, \& Van Scoy, 1995). However, this has not been researched in early childhood education programs where practitioners represent individuals with various back- 
grounds and dispositions. In addition, practitioners' inclinations to reflect on personal experiences and practice may influence whether they achieve meaningful, lasting change. Reference to work on adult learning may facilitate more effective professional development efforts in early childhood education. Much more needs to be learned about strategies and techniques that facilitate meaningful self-reflection in early childhood practitioners and their effects on implementation and generalization of practice.

Between-person (relational) variables. In addition to intrapersonal characteristics of participants engaged in professional development activities, interpersonal relationships among them appear to be important. Early childhood teachers' responsiveness to coaching has been found to be related to the "fit" between individuals' goals and preferences for coaching and the style and orientation of the coach (Brown, Knoche, Edwards, \& Sheridan, this issue; McCormick \& Brennan, 2001). The specific features that appear to be most salient in affecting the relationship in positive or negative ways, however, are not clear. Personal characteristics of the trainer/coach/consultant and of the early childhood teacher may moderate the formation of a professional development relationship and influence the efficacy of a particular professional development approach; this requires further research attention.

The ability of coaches and consultants to establish positive relationships with teachers and consultees has been identified as a critical factor to the success of the coaching/consultation process (Green et al., 2006). Establishing a positive, constructive professional development relationship with teachers engaged in professional development activities seems essential if the goals of the activities are to be met and may influence the effects of training, coaching, or consulting in dynamic ways. For example, direct feedback and instruction may be received more favorably by an early childhood teacher who has a long-standing relationship with a coach characterized by trust in his or her expertise and experience (Hattie \& Timperley, 2007) than by an early childhood teacher who is working with an unfamiliar coach with whom trust has not been developed. These initial responses may have cascading effects. Relationship factors such as trust, shared goals, respect, flexibility, and commitment are often not addressed explicitly and/or systematically in planning professional development events and activities, yet they may be related to the degree to which the process evolves and ultimately supports important behavior change and positive child outcomes (Gallacher, 1997). Indeed, the degree to which the relationship between a coach and practitioner mediates the attainment of professional development goals is not well understood and is in need of empirical attention.

\section{Contextual and Systemic Variables}

The physical, social, and cultural contexts of early childhood education likely influence the structures and processes surrounding professional devel- 
opment at many levels. Recognition and assessment of context and its effects on performance is therefore important (Gallacher, 1997; Welch-Ross et al., 2006). At a basic level, context influences whether professional development opportunities are available, how and when they are delivered, what is expected, how they are financed, who is involved, and what roles individuals play. Although these variables are readily apparent in practice settings, very little attention has been afforded them in the research literature. The potential role of these variables in moderating the effect of professional development activities on desired professional outcomes is ripe for empirical study.

The settings within which early childhood practice takes place are heterogeneous communities, and professionals' needs across divergent settings likely vary due to background, training, experience, perspective, and orientation. Characteristics of the work setting (e.g., school-based early childhood center, home-based services, stand-alone private child care, federally or state-funded preschool program), age of children served (infants, toddlers, preschoolers), number of other adults in the setting, and adultto-child ratio may influence the nature and structure of professional development and positively or negatively influence the outcome of professional development efforts. Furthermore, the culture of the workplace-including the goals and mission of the agency, workplace morale, quality of the work environment, length of work hours, size of caseload, opportunities for teacher collaboration, quality of administrative leadership, and agency-induced requirements that extend beyond support for children's learningare variables of the job context that may relate to the efficacy of various forms of professional development (Joyce \& Showers, 2002). Careful investigation aimed at uncovering context variables would go far in specifying what methods of professional development are useful for certain practitioners across distinctive and unique work settings and conditions. For example, experienced teachers with relatively small class enrollments and familiar children may respond promptly and competently to cost-efficient group training techniques. However, new teachers concerned about on-the-job survival, new curricula, and children's safety in unfamiliar settings may require more individualized coaching or CoP efforts to effect change or application of targeted practices.

\section{Means to Promote Sustained Change}

The sustainability of professional development efforts is a topic of great interest among the research, practice, and policy communities alike. The maintenance of skills beyond immediate training and initial supports, and efforts related to creating climates conducive for ongoing improvement, are critical to enhancing quality in early childhood environments (Johnson \& Johnson, 1989). Information on the intensity and duration of professional support needed to promote sustained change would help establish meaningful parameters for both structure and process. It is likely that the culture of professional development in the agencies or settings where early 
childhood practitioners work will influence in part their ability to sustain positive change in practice (Gallacher, 1997; Welch-Ross et al., 2006). In situations where external resources are used to deliver professional development (e.g., grant-supported projects), empirically based methods need to be determined to sustain effective professional development activities and effective practice once external resources are removed. It seems warranted that professional development models that employ external trainers, coaches, consultants, or facilitators also identify means of transitioning responsibilities for continued study and/or support to individuals or mechanisms internal to the organization ultimately responsible for practice.

CoP models may provide one framework for establishing internal sources or networks of support and building the capacity of agencies to promote a culture of ongoing and sustained professional development (Wenger, 1998). A host of empirical issues must be addressed, however, if CoP models are to be perceived as vehicles by which formal training and coaching efforts can be sustained. For instance, the relationship between specific strategies (e.g., inquiry and problem-solving methods), structures (e.g., timing, membership), and skills (e.g., facilitator leadership behaviors) is in need of articulation. Furthermore, the manner in which they interact to influence the attainment of goals and objectives for a CoP is in need of empirical investigation. Efforts to identify the manner in which person and relationship variables interact within the $\mathrm{CoP}$ structure and influence its effects is another area worthy of research. At a basic level, the organizational mechanisms by which CoPs can be most effective and sustainable in early childhood settings over time are unknown. As with other forms of professional development, the manner in which these factors interact with member characteristics and resources is unclear.

An additional systemic issue related to sustainability of effective professional development is the cost of delivery and return on investment. The "real" costs associated with personnel time (including that of the trainer/ coach/consultant, early childhood teacher, and other support staff), resources (training materials, reflection tools, distance-learning courses), and travel to meetings and site visits likely impact the ability of agencies to maintain a highly trained and supported workforce. Associated costs may also be present, particularly if initial stages of professional development uncover the need for extensive levels of support or individualized training, coaching, or other support for extended periods of time. Studying the costbenefit ratio of various forms of professional development within the context of experimental investigations of efficacy is an area of critical importance for practice and policy communities alike (Welch-Ross et al., 2006).

\section{CONCLUSIONS}

The field of early childhood education is enjoying a time of rapid growth and new discoveries. Efforts to help practitioners remain abreast of 
new knowledge, acquire refined skills, and utilize evidence-based practices include specialized training, coaching/consulting, and CoPs. Although growing evidence indicates that training alone is insufficient and that ongoing support efforts are necessary to transfer knowledge and skill to practice, little is known about how various forms of professional development operate and interact to enhance advanced learning and generalization to behavior and, ultimately, to improve program quality. Critical research needs still exist to uncover process variables that promote change in practitioners' knowledge, skills, and dispositions that are indicative of effective practice. A research agenda in early childhood professional development is needed (a) to unpack basic information on processes that promote the development of the skills and competencies necessary to provide high-quality, evidence-based early childhood experiences; and (b) to identify interactions that occur between form and process and that influence the outcomes of professional development efforts. Research is needed that evaluates relative contributions of professional and personal characteristics of staff, content of training, coaching/consulting practices, roles and relationships, systemic and contextual variables, and the interaction effects among them (Schoenwald, Sheidow, \& Letourneau, 2004), to name a few.

Many opportunities for research on professional development are available within the context of ongoing empirical studies investigating the efficacy of specific interventions being delivered in early childhood settings. We urge researchers, whenever possible, to embed a selection of the proposed research questions into field studies from which data on professional development can be collected within the course of ongoing investigations. Specifically, in many instances it is likely that professional development is occurring as part of field trials, yet little discussion on professional development practices or lessons learned is provided in publications. To advance our understanding of professional development in early childhood we needs to be more complete information than is currently provided in most reports of findings. As a starting point, descriptions of professional development models utilized in interventions need to be specified in research reports. Subsequently, direct and intentional efforts to create linkages between empirical research and practice are necessary. For example, questions addressing the relationship between focus of professional development, type of feedback provided, or duration and intensity of coaching and growth in the early childhood practitioner could be addressed through secondary analyses using regression or correlational techniques. Studies of planned variations of professional development delivery (e.g., individual teacher vs. teacher-aide dyad, 1- vs. 2-year support) may help elucidate the effects of professional development efforts with greater precision. Mixed method designs integrating rigorous experimental trials with qualitative interviews or focus groups about the coach-learner relationship, match to philosophical beliefs about practice, or a host of other professional development processes could also be important additions to empirical research. 
As best practices in professional development are integrated into early childhood intervention studies and methods for enhancing outcomes through professional supports are implemented and documented, it would be highly beneficial for thoughtful discussions to emerge along with focused research studies designed to examine these variables. Such discussions and subsequent studies will provide critical information for fellow researchers whose primary aims are identifying evidence-based interventions for children and families but who need to implement professional development models to enhance the fidelity of their intervention implementations. Likewise, such studies will be highly valuable to the early childhood practice and policy communities where translation of the research base into evidence-based exemplars for best practice is needed. Indeed, such translation is the ultimate goal.

\section{ACKNOWLEDGMENTS}

The development of this article was supported by a grant awarded to Drs. Susan Sheridan and Carolyn Pope Edwards by the U.S. Department of Health and Human Services - National Institute of Child Health and Human Development, Administration for Children and Families and Office of the Assistant Secretary for Planning and Evaluation; and the U.S. Department of Education - Office of Special Education and Rehabilitative Services (Grant \#1R01H00436135). The opinions expressed herein are those of the investigators and do not reflect the funding agencies.

We would like to acknowledge the Interagency School Readiness Consortium (ISRC) Task Force on Early Childhood Professional Development, which participated in the early stages of this work, particularly for their conceptual contributions to research directions in early childhood professional development. In addition to the present authors, members include Karen Bierman, Harriet Darling, Karen Diamond, Celene Domitrovich, Jason Downer, Bridget Hamre, Joan Lieber, Sam Odom, Bob Pianta, and Gloria Rhule. Staff from federal agencies also participated, including Anne Wolf, Martha Moorehouse, and Ivelisse Martinez-Beck.

Likewise, we acknowledge the many early childhood educators, coaches, and consultants who worked with us over the years for their commitment to excellence and feedback regarding our efforts at professional development. They are the true experts who provided invaluable experiences and insight into the processes that promote positive outcomes for children and families.

\section{REFERENCES}

Abramson, S. (2008) Co-inquiry: Documentation, communication, action. - Voices of Practitioners-Co-inquiry Meetings for Facilitated Professional Interchange. Accessed April 24, 2009 at http://journal.naeyc.org/btj/vp/pdf/Voices_Abramson_Co-Inquiry.pdf

Ager, A. and O'May, F. (2001) Issues in the definition and implementation of "best practice" for staff delivery of interventions for challenging behaviour. Journal of Intellectual $\mathcal{E}$ Developmental Disability 26, pp. 243-256. 
Bennett, W. E. (1987) Small group instructional diagnosis: A dialogic approach to instructional improvement for tenured faculty. Journal of Staff, Program, and Organizational Development $\mathbf{5}$, pp. 100-104.

Blase, K. A., Fixsen, D. L., and Phillips, E. L. (1984) Residential treatment for troubled children: Developing service systems. In Paine, S. C., Bellamy, G. T., and Wilcox, B. (eds.), Human services that work: From innovation to standard practice pp. 149-165. Brookes, Baltimore

Bray, J. N., Lee, J., Smith, L. L., and Yorks, L. (2000) Collaborative inquiry in practice: Action, reflection and making meaning. Sage, Thousand Oaks, CA

Brown, J., Knoche, L. L., Edwards, C. P., and Sheridan, S. M. (2009) Professional development to support parent engagement: A case study of early childhood practitioners. Early Education and Development 20, pp. 482-506.

Buysse, V. and Wesley, P. (2005) Consultation in early childhood settings. Brookes, Baltimore

Candy, P. C. (1991) Self-direction for lifelong learning: A comprehensive guide to theory and practice. Jossey-Bass, San Francisco

Cannon, G. S., Idol, L., and West, J. F. (1992) Educating students with mild handicaps in general classrooms: Essential teaching practices for general and special educators. Journal of Learning Disabilities 25, pp. 300-317.

Clarke-Stewart, K. A., Vandell, D. L., Burchinal, M., O'Brien, M., and McCartney, K. (2002) Do regulable features of child care homes affect children's development?. Early Childhood Research Quarterly 17, pp. 52-86.

Dall'Alba, G. and Sandberg, J. (2006) Unveiling professional development: A critical review of stage models. Review of Educational Research 76, pp. 383-412.

Davis, D. A. (1995) Changing physician performance: A systematic review of the effect of continuing medical education strategies. Journal of the American Medical Association 274, pp. 700-705.

Dickinson, D. K. and Caswell, L. C. (2007) Building support for language and early literacy in preschool classrooms through in-service professional development: Effects of the Literacy Environment Enrichment Program (LEEP). Early Childhood Research Quarterly 22, pp. 243-260.

Dreyfus, H. L. and Dreyfus, S. E. (1986) Mind over machine: The power of human intuition and expertise in the era of the computer. Free Press, New York

Duff, R., Brown, E., and Van Scoy, I. (1995) Reflection and self-evaluation: Keys to professional development. Young Children 50, pp. 81-88.

Early, D. M., Maxwell, K. L., Burchinal, M., Bender, R. H., Ebanks, C. Henry, G. T., et al. (2007) Teachers' education, classroom quality, and young children's academic skills: Results from seven studies of preschool programs. Child Development 78, pp. 558-580.

Farrer, J., Alkon, A., and To, K. (2007) Child care health consultation programs: Barriers and recommendations. Maternal and Child Health 11, pp. 111-118.

File, N. (1994) Children's play, teacher-child interactions, and teacher beliefs in integrated early childhood programs. Early Childhood Research Quarterly 9, pp. 223-240.

Fixsen, D. L., Naoom, S. F., Blase, K. A., Friedman, R. M., and Wallace, F. (2005) Implementation research: A synthesis of the literature. University of South Florida, Louis de la Parte Florida Mental Health Institute, The National Implementation Research Network, Tampa

Fleet, A. and Patterson, C. (2001) Professional growth reconceptualized: Early childhood staff searching for meaning. Early Childhood Research and Practice 3:2; online at http:// ecrp.uiuc.edu/v3n2/fleet.html

Fukkink, R. G. and Lont, A. (2007) Does training matter? A meta-analysis and review of caregiver training studies. Early Childhood Research Quarterly 22, pp. 294-311. 
Gallacher, K. K. (1997) Supervision, mentoring, and coaching: Methods for supporting personnel development. In Winton, P. J., McCollum, J. A., and Catlett, C. (eds.), Reforming personnel preparation in early intervention: Issues, models, and practical strategies, pp. 191214. Brookes, Baltimore

Girolametto, L., Weitzman, E., and Greenberg, J. (2003) Training day care staff to facilitate children's language. American Journal of Speech-Language Pathology 12, pp. 299-311.

Green, B. L., Everhart, M., Gordon, L., and Garcia-Gettman, M. (2006) Characteristics of effective mental health consultation in early childhood settings: Multi-level analysis of a national survey. Topics in Early Childhood Special Education 26, pp. 142-152.

Greene, K. (2004) Professional development in inclusive early childhood settings: Can we create communities of practice through lesson study?, PhD dissertation, University of North Carolina at Chapel Hill.

Guskey, T. R. (2000) Evaluating professional development. Corwin Press, Thousand Oaks, CA

Guskey, T. R. (2001) Helping standards make the grade. Educational Leadership 59, pp. 20-27.

Hall, G. E. and Hord, S. M. (2001) Implementing change: Patterns, principles, and potholes. Allyn \& Bacon, Boston

Hanft, B., Rush, D., and Shelden, M. (2004) Coaching families and colleagues in early childhood. Brookes, Baltimore

Harvard Family Research Project. (Spring 2006) Family involvement in early childhood education. Cambridge, MA

Hattie, J. and Timperley, H. (2007) The power of feedback. Review of Educational Research 77, pp. 81-112.

Helm, J. H. (2007) Energize your professional development by connecting with a purpose: Building communities of practice. Young Children 62, pp. 12-16.

Himley, M. and Carini, P. F. (2000) Another angle: Children's strengths and school standards. Teachers College Press, New York

Johnson, D. W. and Johnson, R. T. (1989) Cooperation and competition: Theory and research. Interaction Book, Edina, MS

Joyce, B. and Showers, B. (2002) Student achievement through staff development, 3rd ed., Association for Supervision and Curriculum Development, Alexandria, VA

Justice, L. M., Mashburn, A. J., Hamre, B. K., and Pianta, R. C. (2008) Quality of language and literacy instruction in preschool classrooms serving at-risk pupils. Early Childhood Research Quarterly 23, pp. 51-68.

Katz, L. G. (1992) What should young children be learning? ERIC Clearinghouse on Elementary and Early Childhood Education, Urbana, IL. ERIC Document Reproduction Service No. ED290554.

Katz, L. G. Katz, L. G. (ed.) (1995) Strike: Dispositions in early childhood education. Talks with teachers of young children: A collection. Ablex, Norwood, NJ

Kealey, K. A., Peterson Jr., A. V., Gaul, M. A., and Dinh, K. T. (2000) Teacher training as a behavior change process: Principles and results from a longitudinal study. Healthy Education \& Behavior 27, pp. 64-81.

Kennedy, D. (2004) The role of the facilitator in a community of philosophical inquiry. Metaphilosophy 35, pp. 744-765.

Knoff, H. M., McKenna, A. E., and Riser, K. (1991) Toward a consultant effectiveness scale: Investigating the characteristics of effective consultants. School Psychology Review 20, pp. 81-96.

Langer, G. M., Colton, A. B., and Goff, L. S. (2003) Collaborative analysis of student work. Association for Supervision and Curriculum Development, Alexandria, VA 
Lave, J. and Wenger, E. (1991) Situated learning: Legitimate peripheral participation. Cambridge University Press, Cambridge, UK

Lewis, C. (2002) Lesson study: A handbook of teacher-led instructional change. Research for Better Schools, Philadelphia

Maloney, D. M., Phillips, E. L., Fixsen, D. L., and Wolf, M. M. (1975) Training techniques for staff in group homes for juvenile offenders. Journal of Criminal Justice and Behavior 2, pp. 195-216.

Martinez-Beck, I. and Zaslow, M. (2006) Introduction: The context for critical issues in early childhood professional development. In Zaslow, M. and Martinez-Beck, I. (eds.), Critical issues in early childhood professional development, pp. 1-16. Brookes, Baltimore

Maxwell, K. L., Field, C. C., and Clifford, R. M. (2006) Toward better definition and measurement of early childhood professional development. In Zaslow, M. and MartinezBeck, I. (eds.), Critical issues in early childhood professional development, pp. 21-48. Brookes, Baltimore

Maxwell, L. E. (2006) Using environment-behavior research to inform parent education and early childhood caregivers' training programs. Environmental Design Research Association, Atlanta, GA

McCormick, K. M. and Brennan, S. (2001) Mentoring the new professional in interdisciplinary early childhood education: The Kentucky Teacher Internship Program. Topics in Early Childhood Special Education 21, pp. 131-144.

McWilliam, R. A., Tocci, L. and Harbin, G. L. (1998) Family-centered services: Service providers' discourse and behavior. Topics in Early Childhood Special Education 18, pp. 206-221.

Paris, S. G. and Winograd, P. (1990) How metacognition can promote learning and instruction. In Jones, B. F. and Idol, L. (eds.), Dimensions of thinking and cognitive instruction, pp. 15-52. Erlbaum, Hillsdale, NJ

Peaslee, A., Snyder, I. and Casey, P. B. (2007) Making our thinking visible: Using documentation for professional development. Young Children 62, pp. 28-29.

Pianta, R. C. (2006) Standardized observation and professional development: A focus on individualized implementation and practices. In Zaslow, M. and Martinez-Beck, I. (eds.), Critical issues in early childhood professional development, pp. 231-254. Brookes, Baltimore

Project Zero, Cambridgeport Children's Center, Cambridgeport School, Ezra H. Baker School, \& John Simpkins School (2003) Making teaching visible: Documenting individual and group learning as professional development. Project Zero, Cambridge, MA

Ramey, S. L. and Ramey, C. T. (2008) Establishing a science of professional development for early education programs: The knowledge application information systems theory of professional development. In Justice, L. and Vukelich, C. (eds.), Achieving excellence in preschool literacy instruction, pp. 41-64. Guilford Press, New York

Rhodes, S. M. and Hennessy, E. (2000) The impact of training on workers in early childhood education: An evaluation of the Foundation Course in Playgroup Practice. Early Childhood Research Quarterly 15, pp. 559-576.

Riley, D. A. and Roach, M. A. (2006) Helping teachers grow: Toward theory and practice of an "emergent curriculum" model of staff development. Early Childhood Education Journal 33, pp. 363-370.

Schoenwald, S. K., Sheidow, A. J., and Letourneau, E. J. (2004) Toward effective quality assurance in evidence-based practice: Links between expert consultation, therapist fidelity, and child outcomes. Journal of Clinical Child and Adolescent Psychology 33, pp. 94-104.

Sheridan, S. M. and Kratochwill, T. R. (2008) Conjoint behavioral consultation: Promoting family-school connections and interventions. Springer, New York 
Showers, B., Joyce, B., and Bennett, B. (1987) Synthesis of research on staff development: A framework for future study and a state-of-the-art analysis. Educational Leadership 45, pp. 77-87.

Spodek, B. (1996) The professional development of early childhood teachers. Early Child Development and Care 115, pp. 115-124.

Stremmel, A. (2008) The value of teacher research: Nurturing professional and personal growth through inquiry. Accessed January 10, 2009 at http://journal.naeyc.org/btj/vp/pdf/ Voices-Stremmel.pdf

Taylor, B. M., Pearson, P. D., Peterson, D. S., and Rodriguez, M. C. (2003) Reading growth in high-poverty classrooms: The influence of teacher practices that encourage cognitive engagement in literacy learning. Elementary School Journal 104, pp. 3-28.

Taylor, B. M., Pearson, P. D., Peterson, D. S., and Rodriguez, M. C. (2005) The CIERA school change framework: An evidence-based approach to professional development and school reading improvement. Reading Research Quarterly 40, pp. 40-69.

Tout, K., Zaslow, M. and Berry, D. (2006) Quality and qualifications: Links between professional development and quality in early care and education settings. In Zaslow, M. and Martinez-Beck, I. (eds.), Critical issues in early childhood professional development, pp. 77-110. Brookes, Baltimore

VanderVen, K. (1988) Pathways to professional effectiveness for early childhood educators. In Spodek, B., Saracho, O. N., and Peters, D. L. (eds.), Professionalism and the early childhood practitioner, pp. 137-160. Teachers College Press, New York

Welch-Ross, M., Wolf, A., Moorehouse, M., and Rathgeb, C. (2006) Improving connections between professional development research and early childhood policies. In Zaslow, M. and Martinez-Beck, I. (eds.), Critical issues in early childhood professional development, pp. 369-394. Brookes, Baltimore

Wenger, E. (1998) Communities of practice: Learning, meaning, and identity. Cambridge University Press, New York

Wenger, E., McDermott, R., and Snyder, W. (2002) Cultivating communities of practice: A guide to managing knowledge. Harvard Business School Press, Cambridge, MA

Wesley, P. W. and Buysse, V. (2006) Building the evidence base through communities of practice. In Buysse, V. and Wesley, P. W. (eds.), Evidence-based practice in the early childhood field, pp. 161-194. Zero to Three Press, Washington, DC

Yorks, L. (2005) Adult learning and the generation of new knowledge and meaning: Creating liberating spaces for fostering adult learning through practitioner-based collaborative action inquiry. Teachers College Record 107, pp. 1217-1244.

Zaslow, M. and Martinez-Beck, I. (eds.) (2006) Critical issues in early childhood professional development. Brookes, Baltimore 